\title{
Consumo e digestibilidade dos nutrientes em cabras Moxotó recebendo dietas com diferentes níveis de feno de maniçoba ${ }^{1}$
}

\section{Marcos Jácome de Araújo², Ariosvaldo Nunes de Medeiros ${ }^{3}$, Francisco Fernando Ramos de Carvalho ${ }^{4}$, Divan Soares da Silva ${ }^{3}$, Ellio Celestino de Oliveira Chagas ${ }^{5}$}

\author{
${ }^{1}$ Pesquisa financiada pelo CNPq e BNB. \\ 2 Programa de Doutorado Integrado em Zootecnia da UFPB/UFRPE/UFC - CEP: 58.397-000 - Areia - PB. \\ ${ }^{3}$ Depto. Zootecnia/CCA/UFPB, Campus de Areia-PB - CEP: 58.397-000. \\ ${ }^{4}$ Depto. Zootecnia/UFRPE, Recife - PE - CEP: 52.171-900 - Recife - PE. \\ ${ }^{5}$ Escola Agrotécnica Federal de Senhor do Bonfim - BA - CEP: 48970-000.
}

RESUMO - Objetivou-se com este trabalho avaliar a utilização do feno de maniçoba (Manihot glaziovii Muell. Arg.) em diferentes níveis $(30,40,50$ e 60\%) sobre os consumos e as digestibilidades de matéria seca (MS), matéria orgânica (MO), proteína bruta (PB), energia bruta (EB), extrato etéreo (EE), carboidratos totais (CT), carboidratos não-fibrosos (CNF), fibra em detergente neutro (FDN) e fibra em detergente ácido (FDA) e os consumos de água e nutrientes digestíveis totais (NDT). Utilizaram-se oito cabras da raça Moxotó, multíparas, com aproximadamente 60 dias de lactação, pesando $44,26 \pm 4,23 \mathrm{~kg}$, em delineamento quadrado latino duplo $4 \times 4$, com quatro tratamentos, quatro períodos e quatro animais. Cada período teve duração de 15 dias (10 de adaptação dos animais às dietas e 5 para coleta de dados). Utilizou-se a fibra em detergente ácido indigestível (FDAi) como indicador interno para estimativa da produção de matéria seca fecal. A utilização do feno de maniçoba nos níveis de 30, 40, 50 e 60\% nas dietas para cabras em lactação não alterou os consumos de MS, MO, PB, EE, MM e CT. Os consumos de CNF, NDT e água diminuíram linearmente com o aumento no nível de feno de maniçoba nas dietas, enquanto os de FDN e FDA (kg/dia, \%PC e g/kg0,75) aumentaram linearmente. A digestibilidade aparente de MS, MO, PB, EE, CT, CNF, EB e FDA reduziu linearmente, enquanto a da FDN não se alterou com o aumento dos níveis de feno na dieta.

Palavras-chave: alimentação, forrageira nativa, Manihot glaziovii Muell. Arg, valor nutritivo

\section{Intake and digestibility of nutrients in Moxotó dairy goats fed diets with different Maniçoba hay levels}

\begin{abstract}
This research was conducted with the objective of evaluating the use of different Maniçoba hay (Manihot glaziovii Muell. Arg) levels (30, 40,50 and 60\%) on intake and apparent digestibility of dry matter (DM), organic matter $(\mathrm{OM})$, crude protein (CP), gross energy (GE), ether extract (EE), total carbohydrates (TCHT), non fiber carbohydrates (NFC), neutral detergent fiber (NDF), acid detergent fiber (ADF), water intake (WI), besides total digestible nutrients intake (TDNI). Eight multiparous Moxotó dairy goats with initial weight of 44,26 $\pm 4,23 \mathrm{~kg}$ were assigned to two $4 \times 4$ Latin squares design, with four treatments, four experimental periods and four animals. Each experimental period lasted 15 days (ten days for animal adaptation to diets and five days for feed, refusal and feces collection. Indigestible acid detergent fiber (iADF) was used as an internal marker to estimate fecal dry matter yield. The use of Maniçoba hay in the levels $(30,40,50$ and 60\%) in diets did not affect the DM, OM, CP, EE, MM, and TCHT intakes. The NFC, TDN and water intakes decreased linearly with the increase of dietary hay levels while NDF and ADF ( $\mathrm{kg} / \mathrm{day} ; \% \mathrm{BW}$ and $\mathrm{g} / \mathrm{kg}^{0.75}$ ) intakes increased linearly. The apparent DM, OM, CP, EE, CHT, NFC, GE and ADF digestibility decreased linearly while the NDF digestibility was not affected with the increase in the dietary hay levels.
\end{abstract}

Key Words: feeding, Manihot glaziovii Muell. Arg, native forage, nutritive value

\section{Introdução}

O sistema de produção de caprinos na região semi-árida do nordeste brasileiro é basicamente voltado à exploração extensiva ou semi-intensiva, com animais nativos, bem adaptados, tendo como base de alimentação a caatinga, utilizada muitas vezes como única fonte de forragem, todavia, no período de estiagem, quando não há suporte forrageiro suficiente para permitir produção animal satisfatória, tornam-se necessárias práticas de manejo 
diferenciadas, com alternância do sistema de produção e do uso de forragens conservadas na forma de feno ou silagem de espécies nativas ou adaptadas ao meio, que possibilitem suplementar nutricionalmente os animais e manter ou até melhorar os índices de produção.

Uma estratégia cada vez mais utilizada no período da seca para a caprinocultura leiteira, quando se necessita ter produção de leite contínua e bem distribuída ao longo do ano, é a intensificação no modelo de produção neste período com o recolhimento dos animais a centros de manejo ou pequenas áreas para o arraçoamento mais adequado, possibilitando inclusive descanso nas áreas de pastagem, com manejo mais adequadamente sustentável do ecossistema caatinga.

O cultivo diversificado de opções forrageiras nativas e/ou introduzidas, anuais e/ou perenes para a produção de feno e/ou silagem, somado a outras opções como resíduos agroindustriais e outros ingredientes de potencial regional, utilizados de forma planejada, principalmente no período crítico do ano, pode deslocar a eficiência dos sistemas de produção pecuária e em particular da ovinocaprinocultura do semi-árido nordestino (Araújo et al., 2003). Além disso, essas alternativas alimentares devem possuir o mínimo de concentrado e o máximo de ingredientes que possam ser produzidos ou adquiridos pelos próprios criadores nos mais diversos sistemas de produção.

Neste contexto, estudos comprovam que a maniçoba, planta nativa da caatinga, deve ser considerada um recurso forrageiro de boa qualidade e pode ser cultivada de forma sistemática para essa finalidade, tornando-se uma realidade alimentar para caprinos e ovinos, aumentando a eficiência produtiva desses animais (Soares \& Salviano, 2000; Castro et al., 2007; Silva et al., 2007).

Com este estudo objetivou-se avaliar o consumo e a digestibilidade dos nutrientes em cabras da raça Moxotó da linhagem leiteira alimentadas com diferentes níveis de feno de maniçoba (Manihot glaziovii Muell. Arg.) na dieta.

\section{Material e Métodos}

Este experimento foi conduzido na Unidade de Pesquisa em Pequenos Ruminantes da Estação Experimental de São João do Cariri, pertencente ao Centro de Ciências Agrárias da Universidade Federal da Paraíba, no município de São João do Cariri - PB, no período de 16 de julho a 16 de setembro de 2004.

A cidade de São João do Cariri classifica-se como região quente de tendência tropical, com temperaturas médias anuais de $26^{\circ} \mathrm{C}$, precipitações de $395 \mathrm{~mm}$ anuais, nos últimos dez anos com distribuição irregular, observando-se estação seca com duração superior a oito meses e umidade relativa do ar em torno de $68 \%$ (Bacia Escola/UFCG).

Foram utilizadas oito cabras da raça Moxotó com peso corporal de 44,26 4,23 kg e média de 60 dias de lactação. Os animais foram mantidos em regime de confinamento em galpão coberto com telhas de barro, baias individuais feitas de tela nas dimensões $1,5 \times 2,5 \mathrm{~m}$, piso de chão batido, providas de comedouro e bebedouro. A água foi fornecida à vontade e o consumo quantificado diariamente durante $\mathrm{o}$ período de coleta.

O experimento teve duração de 60 dias e foi composto de quatro períodos de 15 dias. Os primeiros dez dias de cada período foram utilizados para adaptação dos animais às dietas experimentais e os cinco dias seguintes destinados à coleta dos dados.

Os tratamentos consistiram de rações completas, com $30,40,50$ ou $60 \%$ de feno de maniçoba. A maniçoba utilizada na confecção do feno foi colhida em áreas de ocorrência natural na caatinga. As plantas encontravam-se em estágio vegetativo de floração e início de frutificação. O material colhido foi triturado em ensiladeira, espalhado em lonas plásticas e revirado freqüentemente, para desidratação até o ponto de feno. Após a fenação, todo o material foi moído em máquina tipo “DMP” (desintegrador, moedor e picador), utilizando-se peneira de $10 \mathrm{~mm}$, e misturado aos outros ingredientes das rações experimentais.

As dietas foram formuladas segundo recomendações do NRC (1981) para atender às exigências nutricionais de cabras em lactação com produção de $2 \mathrm{~kg} /$ cabra/dia e $4 \%$ de gordura de leite (Tabelas 1 e 2). A alimentação foi fornecida na forma de mistura completa, em duas refeições diárias, logo após as ordenhas, às $8 \mathrm{~h}$ e às $16 \mathrm{~h}$. Para garantir consumo à vontade, trabalhou-se com uma sobra em torno de $20 \%$ do oferecido.

Os ingredientes, as dietas e as sobras foram analisadas de acordo com Silva \& Queiroz (2002). Para determinação da lignina (LIG), foi usada metodologia descrita por Van Soest (1967), utilizando ácido sulfúrico a 72\%. Para determinação das frações da parede celular, fibra em detergente neutro (FDN) e fibra em detergente ácido (FDA), utilizou-se metodologia recomendada pelo fabricante do aparelho ANKON, da Ankon Technology Corporation com modificação, utilizando-se sacos de TNT gramatura $100 \mathrm{~mm}$, confeccionados no Laboratório de Nutrição Animal. Em todas as amostras, a FDN e a FDA foram corrigidas para cinza e proteína; os resíduos da digestão em detergente neutro e detergente ácido foram incinerados em mufla a $600^{\circ} \mathrm{C}$ por 4 horas e a correção para proteína foi efetuada 
Tabela 1 - Composição (\%MS) dos ingredientes das dietas experimentais

\begin{tabular}{|c|c|c|c|c|}
\hline Nutriente $(\%)$ & Farelo de milho ${ }^{1}$ & Farelo de soja & Farelo de trigo & Feno de maniçoba \\
\hline Matéria seca & 89,16 & 89,66 & 88,88 & 89,71 \\
\hline Matéria orgânica & 96,85 & 93,62 & 93,64 & 94,59 \\
\hline Matéria mineral & 3,15 & 6,38 & 6,36 & 5,41 \\
\hline Proteína bruta & 11,08 & 48,92 & 15,08 & 10,56 \\
\hline Extrato etéreo & 10,86 & 2,06 & 2,47 & 2,00 \\
\hline FDNep & 28,48 & 15,50 & 47,54 & 53,72 \\
\hline FDAcp & 6,88 & 10,04 & 17,08 & 44,52 \\
\hline Lignina & 2,85 & 2,48 & 5,83 & 13,58 \\
\hline Carboidratos totais & 74,91 & 42,64 & 76,09 & 84,96 \\
\hline CNFcp & 46,43 & 27,14 & 28,53 & 31,25 \\
\hline Energia metabolizável (Mcal/kg MS $)^{2}$ & 3,15 & 9,90 & 3,00 & 1,83 \\
\hline PIDN & 1,85 & 5,28 & 4,5 & 2,92 \\
\hline PIDA & 0,70 & 2,25 & 0,69 & 1,58 \\
\hline
\end{tabular}

${ }^{1}$ Subproduto da fabricação de flocos de milho.

2 Energia metabolizável = energia digestível × 0,82 (NRC, 1989).

FDNcp = fibra em detergente neutro corrigida para cinzas e proteína; FDAcp = fibra em detergente ácido corrigida para cinzas e proteína; CNFcp= carboidratos nãofibrosos corrigido para cinzas e proteína; PIDN = proteína insolúvel em detergente neutro; PIDA = proteína insolúvel em detergente ácido.

Tabela 2 - Composição das dietas (\%MS) experimentais

\begin{tabular}{|c|c|c|c|c|}
\hline \multirow[t]{2}{*}{ Ingrediente $(\%)$} & \multicolumn{4}{|c|}{$\%$ de feno de maniçoba } \\
\hline & 30 & 40 & 50 & 60 \\
\hline Feno de maniçoba & 30,34 & 40,39 & 50,39 & 60,37 \\
\hline Farelo de milho & 49,90 & 41,25 & 32,54 & 23,94 \\
\hline Farelo de trigo & 6,85 & 4,88 & 2,93 & 0,98 \\
\hline Farelo de soja & 9,95 & 10,14 & 10,32 & 10,41 \\
\hline Óleo de soja & 0,98 & 1,37 & 1,86 & 2,34 \\
\hline Calcário & 0,98 & 0,98 & 0,98 & 0,98 \\
\hline $\begin{array}{l}\text { Suplemento vitamínico- } \\
\text { mineral }\end{array}$ & 0,98 & 0,98 & 0,98 & 0,98 \\
\hline Matéria seca $(\%)$ & 89,62 & 89,72 & 89,83 & 89,94 \\
\hline Matéria orgânica (\%) & 94,97 & 94,80 & 94,65 & 93,51 \\
\hline Matéria mineral $(\%)$ & 5,03 & 5,20 & 5,35 & 6,49 \\
\hline Proteína bruta (\%) & 14,64 & 14,53 & 14,42 & 14,27 \\
\hline Extrato etéreo (\%) & 7,37 & 6,97 & 6,67 & 6,37 \\
\hline FDNcp $(\%)$ & 35,31 & 37,34 & 39,33 & 41,33 \\
\hline FDAcp (\%) & 19,11 & 22,67 & 26,21 & 29,74 \\
\hline Lignina $(\%)$ & 6,19 & 7,18 & 8,20 & 9,19 \\
\hline Carboidratos totais (\%) & 72,96 & 73,30 & 73,56 & 72,87 \\
\hline CNFcp $(\%)$ & 37,65 & 35,96 & 34,23 & 31,54 \\
\hline PIDN (\%) & 2,63 & 2,65 & 2,74 & 2,79 \\
\hline PIDA $(\%)$ & 1,10 & 1,19 & 1,28 & 1,35 \\
\hline Energia metabolizável ${ }^{1}$ & 2,75 & 2,64 & 2,55 & 2,45 \\
\hline $\begin{array}{l}\text { Nutrientes digestíveis } \\
\text { totais }(\%)^{2}\end{array}$ & 66,77 & 60,56 & 57,02 & 53,70 \\
\hline Cálcio (\%) & 0,79 & 0,82 & 0,85 & 0,88 \\
\hline Fósforo (\%) & 0,41 & 0,40 & 0,39 & 0,38 \\
\hline
\end{tabular}

${ }^{1} \mathrm{EM}(\mathrm{Mcal} / \mathrm{kg} \mathrm{MS})=$ energia digestível $\times 0,82(\mathrm{NRC}, 1989)$.

2 Sniffen et al. (1992).

FDNcp = fibra em detergente neutro corrigida para cinzas e proteína; FDAcp $=$ fibra em detergente ácido corrigida para cinzas e proteína; PIDN = proteín insolúvel em detergente neutro; PIDA = proteína insolúvel em detergente ácido; $\mathrm{CNF} c \mathrm{p}=$ carboidratos não-fibrosos corrigidos para cinzas e proteína.

utilizando a proteína insolúvel em detergente neutro (PIDN) e a proteína insolúvel em detergente ácido (PIDA).

Para a estimativa dos carboidratos totais (CT) utilizou-se equação proposta por Sniffen et al. (1992). Os carboidratosnão-fibrosos (CNF) foram estimados utilizando a equação preconizada por Hall et al. (1999), de modo que a FDN foi corrigida para cinzas e proteína (FDNcp). Na determinação da PIDN e PIDA, foi empregada metodologia descrita por Licitra et al. (1996). Para o cálculo do consumo dos nutrientes digestíveis totais (CNDT) e da porcentagem de NDT, utilizou-se a equação proposta por Sniffen et al. (1992), em que: $\mathrm{CT}=100-(\% \mathrm{~PB}+\% \mathrm{EE}+\%$ Cinzas $) ; \mathrm{CNFcp}=\% \mathrm{CT}-$ $\%$ FDNcp; CNDT $=($ PBing. PBfecal $)+2,25 *$ (EEing.-EEfecal $)$ $+($ CTing. - CTfecal $)$; e a $\%$ NDT $=($ CNDT $/$ CMS $) * 100$.

Utilizaram-se as equações propostas pelo NRC (2001) para estimar os valores energéticos das dietas experimentais e comparar aos valores observados. Na estimativa do teor de NDT para mantença $\left(\right.$ NDT $\left._{1 \mathrm{X}}\right)$ e de energia digestível para mantença $\left(\mathrm{ED}_{1 \mathrm{X}}\right)$ das dietas e dos alimentos utilizados e para calcular a digestibilidade verdadeira dos CNF (DVCNF), com fator de ajuste para processamento (FAP) igual a 1 ; da proteína bruta da forragem (DVPBf) e de concentrados (DVPBc); dos ácidos graxos (DVAG) e da FDN (DVFDN), foram utilizadas as seguintes equações: $\operatorname{NDT}_{1 \mathrm{X}}(\%)=$ $\mathrm{DVCNF}+\mathrm{DVPBc}+\mathrm{DVPBf}+(\mathrm{DVEE} * 2,25)+\mathrm{DVFDN}-7$; $\mathrm{DVCNF}=0,98 *[100-((\mathrm{NDF}-\mathrm{PIDN})+\mathrm{PB}+\mathrm{EE}+$ Cinzas $)$ *FAP; DVPBf $=$ PB $* \exp [-1,2 *(\mathrm{PIDA} / \mathrm{PB})] ; \mathrm{DVPBc}=$ $[1-(0,4 *(\mathrm{PIDA} / \mathrm{PB}))]^{*} \mathrm{~PB} ; \mathrm{DVAG}=\mathrm{EE}-1 . \mathrm{Se} \mathrm{EE}<1, \mathrm{AG}=0$; e a DVFDN $=0,75 *[($ FDN-PIDN)- Lignina $] *$ [1-(Lignina/ $\left.\left.(\text { FDN-PIDN })^{0,667}\right)\right]$.

A energia bruta (EB) foi determinada por meio da oxidação da amostra em bomba calorimétrica, enquanto a energia digestível (ED) foi estimada multiplicando a EB pelo seu coeficiente de digestibilidade da mesma (CDEB), $(\mathrm{ED}=\mathrm{EB} * \mathrm{CDEB})$. A energia metabolizável $(\mathrm{EM})$ foi estimada de acordo com o NRC (1989), em que $\mathrm{EM}=\mathrm{ED} * 0,82$.

O consumo de água, MS e dos nutrientes foi obtido por meio da diferença do oferecido e das sobras, mensurados durante os cinco últimos dias de cada período experimental. 
As sobras dos alimentos foram pesadas pela manhã em sua totalidade e $30 \%$ foi amostrado. Ao serem coletadas, as amostras foram acondicionadas em sacos plásticos com as devidas identificações dos animais, tratamentos e período de coleta e em seguida congeladas a $-10^{\circ} \mathrm{C}$. Ao final de cada período foram descongeladas e homogeneizadas para retirada de uma amostra composta, de aproximadamente $250 \mathrm{~g}$, por animal. As amostras foram pré-secas em estufa com ventilação forçada $\left(55 \mathrm{a} 60^{\circ} \mathrm{C}\right)$ por 72 horas e processadas emmoinho de facas com peneiras de malha de $1 \mathrm{~mm}$.

O consumo dos nutrientes foi estimado por meio da diferença entre o total do nutriente nos alimentos ofertados e o total do nutriente nas sobras. O consumo de nutrientes digestíveis totais (NDT) foi estimado segundo Sniffen et al. (1992), em ensaio de digestibilidade.

Para determinação dos coeficientes de digestibilidade de MS, MO, PB, EE, EB, FDN, FDA, CT e CNF, foram coletadas fezes dos animais, diretamente na porção final do reto, sempre após a primeira ordenha e antes da primeira alimentação, durante os cinco dias de coleta de cada período. As amostras de fezes foram armazenadas a $-10^{\circ} \mathrm{Ce}$, posteriormente, da mesma forma que os alimentos e sobras, foram processadas ao término de cada período experimental.

A estimativa da produção fecal foi feita utilizando-se a fibra em detergente ácido indigestível (FDAi) como indicador interno. As amostras de fezes, alimentos e sobras foram incubadas in vitro em sacos de tecido tipo TNT, por um período de 144 horas, segundo metodologia descrita por Berchielli et al. (2000). A quantidade da amostra incubada foi de 1,0 g para alimentos, sobras e fezes. O material remanescente da incubação foi submetido à extração com detergente ácido e o resíduo considerado FDAi. Para o cálculo de matéria seca fecal (MSF), utilizou-se a equação: MSF $(\mathrm{kg})=($ Indicador consumido $(\mathrm{kg})) /(\%$ do indicador nas fezes) $* 100$.

O coeficiente de digestibilidade aparente (CDA) foi calculado como descrito por Silva \& Leão (1979).

O delineamento experimental utilizado foi o quadrado latino $(4 \times 4)$, sendo quatro animais, quatro períodos e quatro níveis de feno de maniçoba na ração. Foram utilizados dois quadrados simultâneos, com os animais distribuídos aleatoriamente. Os dados foram submetidos à análise de variância e regressão (SAS, 1996), seguindo o modelo matemático:

$$
Y_{i j k l}=\mu+a_{i} / q_{k}+p_{j} / q_{k}+q_{k}+\text { trat }_{.1}+e_{i j k l}
$$

em que: Yijkl = observação do animal $\mathrm{i}$, no período $\mathrm{j}$, no quadrado $\mathrm{k}$, recebendo o tratamento $1 ; \mu=$ média geral; $a_{i} / q_{k}=$ efeito do animal i dentro de quadrado $\mathrm{k} ; p_{j} / q_{k}=$ efeito do período i dentro de quadrado $\mathrm{k} ; q_{k}=$ efeito do quadrado $\mathrm{k}$; trat. . $_{l}=$ efeito do tratamento 1 ; eijkl $=$ erro aleatório associado a cada observação.

\section{Resultados e Discussão}

Os níveis de feno de maniçoba não influenciaram o consumo de MS, independentemente da forma como foi expresso (Tabela 3). O consumo médio de MS foi de 1,95 kg/ dia, equivalente a $4,38 \%$ do PC ou $113,11 \mathrm{~g} / \mathrm{kg}^{0,75}$. O valor médio de 4,38\% PC encontra-se nos níveis sugeridos pelo NRC (1981), de 4 a 5\% do PC, para cabras em lactação com peso vivo de $50 \mathrm{~kg}$ e $2 \mathrm{~L}$ de leite. O principal determinante do desempenho animal é o consumo de nutrientes. Como não houve efeito dos níveis de feno no consumo de MS, acredita-se que os animais ingeriram nutrientes suficientes para atender suas exigências. Além disso, a forma de fornecimento da dieta em mistura completa possivelmente proporcionou quantidade desejável de nutrientes, pois, conforme descrito por Faria (1993), rações completas aumentam em até $20 \%$ o consumo voluntário dos animais.

Existem na literatura diversos trabalhos visando estabelecer o nível ótimo de volumoso em relação ao nível de concentrado em dietas para cabras leiteiras (Kawas et al., 1991; Hussain et al., 1996; Silva et al., 1999; Gonçalves et al., 2001; Goetsch et al., 2001; Zambom et al., 2005), mas os resultados são os mais variados possíveis. O consumo médio de $1,95 \mathrm{~kg} /$ dia de MS encontrado neste estudo foi um pouco elevado em comparação ao relatado pelo AFRC (1998), uma vez que, para animais produzindo 2 litros de leite, pesando $40 \mathrm{~kg}$ de peso vivo, recomenda-se $1,60 \mathrm{~kg} / \mathrm{dia}$ de MS, o que indica a possibilidade do uso de níveis mais elevados de feno em dietas para cabras Moxotó.

Os teores de FDN e FDA na matéria seca total das rações (Tabela 2) aumentaram linearmente à medida que se elevou a porcentagem de feno na dieta, o que pode explicar o comportamento dos consumos de FDN (kg/dia; \%PC e $\left.\mathrm{g} / \mathrm{kg}^{0,75}\right)$ e FDA (kg/dia; \%PC e g/ $\left.\mathrm{kg}^{0,75}\right)$.

Para vacas leiteiras, Mertens (1992) estabeleceu o cálculo da capacidade diária de consumo de FDN como: $(1,2 * \mathrm{PC}) / 100$. Extrapolando essa relação para os animais deste experimento, a capacidade de consumo da FDN seria de 0,53 kg de FDN/dia, abaixo do consumo de FDN observado nesta pesquisa (Tabela 3 ). Ainda de acordo com essa relação, a ingestão de MS seria limitada pelo efeito físico do enchimento do rúmen quando o consumo de FDN fosse de 11 a $13 \mathrm{~g} / \mathrm{kg}$ de PC (Mertens, 1992), no entanto, o consumo de FDN observado neste estudo foi de 14,$38 ; 16,88 ; 17,18$ e $16,90 \mathrm{~g} / \mathrm{kg}$ de PC, respectivamente, para os tratamentos $30,40,50$ e $60 \%$ de feno. 
Tabela 3 - Consumo de matéria seca, fibra em detergente neutro e fibra em detergente ácido em cabras Moxotó em lactação alimentadas com rações contendo feno de maniçoba

\begin{tabular}{|c|c|c|c|c|c|c|c|}
\hline \multirow[t]{2}{*}{ Nutriente } & \multicolumn{4}{|c|}{$\%$ de feno de maniçoba } & \multirow[t]{2}{*}{ Equação } & \multirow[t]{2}{*}{$\mathrm{CV}(\%)$} & \multirow[t]{2}{*}{$\mathrm{R}^{2}(\%)$} \\
\hline & 30 & 40 & 50 & 60 & & & \\
\hline Matéria seca (kg/dia) & 1,94 & 2,06 & 1,91 & 1,91 & $\hat{y}=1,95^{\mathrm{NS}}$ & 11,73 & - \\
\hline Matéria seca (\%PC) & 4,37 & 4,67 & 4,25 & 4,23 & $\hat{y}=4,38^{\mathrm{NS}}$ & 10,64 & - \\
\hline Matéria seca $\left(\mathrm{g} / \mathrm{kg}^{0,75}\right)$ & 112,62 & 120,31 & 110,02 & 109,54 & $\hat{\mathrm{y}}=113,12^{\mathrm{NS}}$ & 10,84 & - \\
\hline Fibra em detergente neutro $(\mathrm{kg} / \mathrm{dia})$ & 0,64 & 0,75 & 0,77 & 0,77 & $\hat{\mathrm{y}}=0,5465+0,0041 * * \mathrm{x}$ & 10,70 & 72 \\
\hline Fibra em detergente neutro (\%PC) & 1,44 & 1,69 & 1,72 & 1,69 & $\hat{\mathrm{y}}=1,2789+0,0079 * * \mathrm{x}$ & 9,18 & 60 \\
\hline Fibra em detergente neutro $\left(\mathrm{g} / \mathrm{kg}^{0,75}\right)$ & 37,06 & 43,47 & 44,40 & 43,81 & $\hat{y}=32,662+0,2116^{* * x}$ & 9,45 & 63 \\
\hline Fibra em detergente ácido (kg/dia) & 0,39 & 0,51 & 0,53 & 0,60 & $\hat{y}=0,2103+0,0066 * x_{x}$ & 11,46 & 93 \\
\hline Fibra em detergente ácido (\%PC) & 0,88 & 1,15 & 1,19 & 1,33 & $\hat{y}=0,5128+0,0138 * * x$ & 10,74 & 91 \\
\hline Fibra em detergente ácido $\left(\mathrm{g} / \mathrm{kg}^{0,75}\right)$ & 22,63 & 29,51 & 30,82 & 34,30 & $\hat{y}=12,963+0,3634 * * x$ & 10,84 & 91 \\
\hline
\end{tabular}

NS não-significativo; ** $(\mathrm{P}<0,01) ; *(\mathrm{P}<0,05)$

Essas relações devem ser utilizadas com cautela, pois foram desenvolvidas com vacas leiteiras de alta produção, alimentadas com forrageiras de clima temperado. Esse fato sugere a necessidade da determinação de indicadores de ingestão de fibra para cabras, especialmente de raças nativas, que possuem maior capacidade de armazenagem de alimentos no rúmen, possivelmente pelo fato de as forrageiras em condições tropicais conterem menor conteúdo de energia, o que faz com que o animal necessite de maiores quantidades de alimento para atender suas exigências.

Os consumos de MO, PB, EE, MM e CT (Tabela 4) não foram influenciados $(\mathrm{P}>0,05)$ pelos níveis de feno nas dietas, cujos valores médios foram de 1,86;0,26;0,12;0,09 e $1,48 \mathrm{~kg} / \mathrm{dia}$, respectivamente. O consumo médio de $0,26 \mathrm{~kg} / \mathrm{dia}$ de PB foi superior ao preconizado pelo AFRC (1998), de 0,20 kg/dia, o que pode estar correlacionado ao elevado consumo de MS.

A ausência de significância no consumo de PB está relacionada ao fato de que as dietas eram isoprotéicas (Tabela 2) e houve mesmo consumo de MS. Além disso, provavelmente não houve seletividade, pois a ração foi fornecida como mistura completa. Da mesma forma, os consumos de MO, EE, MM e CT seguiram a mesma tendência.

O consumo de energia metabolizável (EM) apresentou decréscimo de $0,0249 \%$ para cada $1 \%$ de aumento dos níveis de feno de maniçoba. O NRC (1981) recomenda consumo diário de 4,88 Mcal para um animal de $50 \mathrm{~kg}$ de peso vivo, 2 litros de leite (4\% gordura) e ganho de peso de $50 \mathrm{~g} / \mathrm{dia}$, valor abaixo dos encontrados neste experimento, exceto para a ração com $60 \%$ de feno de maniçoba.
Os consumos de CNF e NDT sofreram influência do nível de feno de maniçoba nas dietas $(\mathrm{P}<0,01)$, apresentando comportamento linear decrescente. Esse fato pode ser explicado pela diminuição dos conteúdos de CNF e NDT nas dietas com o aumento da participação de feno, aumentando assim os consumos de FDN e FDA e considerando que o consumo de MS não diferiu entre as dietas avaliadas.

O consumo de água reduziu linearmente $(\mathrm{P}<0,05)$ com o aumento da participação do feno nas dietas (Tabela 4). Esse comportamento pode ser explicado pelo fato de as dietas com maior proporção de fibra necessitarem de maior tempo de mastigação, estimulando maior taxa de ruminação e maior fluxo de saliva, proporcionando maior taxa de diluição. Ao contrário, os alimentos com maior porcentagem de concentrado, não estimulam ruminação extensa, o que resulta em baixa taxa de diluição, influenciando maior taxa de ingestão de água (Herd, 1993).

Com exceção da FDN, que não foi afetada pelos níveis de feno de maniçoba nas dietas, a digestibilidade de todos os nutrientes estudados foi influenciada linearmente $(\mathrm{P}<0,01)$ de forma negativa pelo aumento do nível de feno na dieta (Tabela 5).

Os coeficientes de digestibilidade da MS variaram de 50,79 a 59,57\% nos níveis de 60 e $30 \%$ de feno de maniçoba nas dietas, respectivamente. A equação de regressão revela redução de $0,3015 \%$ na digestibilidade da MS a cada $1 \%$ de aumento de feno na dieta (Tabela 5). O comportamento linear decrescente da digestibilidade da MS pode ser atribuído à menor concentração de carboidratos totais digestíveis e à menor energia relacionada aos carboidratos estruturais presentes nas rações com maiores proporções de volumoso. 
Tabela 4 - Consumo de nutrientes e água em cabras Moxotó em lactação alimentadas com rações contendo feno de maniçoba

\begin{tabular}{|c|c|c|c|c|c|c|c|}
\hline \multirow[t]{2}{*}{ Variável } & \multicolumn{4}{|c|}{$\%$ de feno de maniçoba } & \multirow[t]{2}{*}{ Equação } & \multirow[t]{2}{*}{$\mathrm{CV}(\%)$} & \multirow[t]{2}{*}{$\mathrm{R}^{2}(\%)$} \\
\hline & 30 & 40 & 50 & 60 & & & \\
\hline Matéria orgânica (kg/dia) & 1,85 & 1,98 & 1,82 & 1,80 & $\hat{y}=1,86^{N S}$ & 11,60 & - \\
\hline Proteína bruta (kg/dia) & 0,27 & 0,28 & 0,24 & 0,25 & $\hat{\mathrm{y}}=0,26^{\mathrm{NS}}$ & 14,88 & - \\
\hline Extrato etéreo $(\mathrm{kg} / \mathrm{dia})$ & 0,13 & 0,13 & 0,11 & 0,12 & $\hat{y}=0,12 \mathrm{NS}$ & 14,72 & - \\
\hline Energina metabolizável (Mcal/dia) & 5,32 & 5,44 & 4,87 & 4,68 & $\hat{y}=6,2004-0,0249 * x$ & 11,57 & 68 \\
\hline Matéria mineral(kg/dia) & 0,08 & 0,09 & 0,08 & 0,12 & $\hat{y}=0,09 \mathrm{NS}$ & 15,64 & - \\
\hline Carboidratos totais $(\mathrm{kg} / \mathrm{dia})$ & 1,46 & 1,57 & 1,47 & 1,43 & $\hat{\mathrm{y}}=1,48^{\mathrm{NS}}$ & 11,27 & - \\
\hline Carboidratos não-fibrosos (kg/dia) & 0,82 & 0,82 & 0,71 & 0,66 & $\hat{\mathrm{y}}=1,0179-0,0059^{* * \mathrm{x}}$ & 14,28 & 87 \\
\hline Nutrientes digestíveis totais ( $\mathrm{kg} / \mathrm{dia})$ & 1,29 & 1,24 & 1,09 & 1,03 & $\hat{y}=1,5842-0,0094 * * x$ & 13,78 & 96 \\
\hline Água (kg/dia) & 4,57 & 4,67 & 4,26 & 4,27 & $\hat{y}=5,0163-0,00128 * x$ & 8,29 & 65 \\
\hline
\end{tabular}

NS não-significativo; ** $(\mathrm{P}<0,01) ; *(\mathrm{P}<0,05)$

Tabela 5 - Digestibilidade dos nutrientes em cabras Moxotó em lactação alimentadas com rações contendo feno de maniçoba

\begin{tabular}{|c|c|c|c|c|c|c|c|}
\hline \multirow[t]{2}{*}{ Nutriente } & \multicolumn{4}{|c|}{$\%$ de feno de maniçoba } & \multirow[t]{2}{*}{ Equação } & \multirow[t]{2}{*}{$\mathrm{CV}(\%)$} & \multirow[t]{2}{*}{$\mathrm{R}^{2}(\%)$} \\
\hline & 30 & 40 & 50 & 60 & & & \\
\hline Matéria seca & 59,57 & 55,39 & 51,58 & 50,79 & $\hat{y}=67,899-0,3015^{* * x}$ & 8,17 & 93 \\
\hline Matéria orgânica & 62,62 & 59,07 & 55,05 & 53,31 & $\hat{y}=71,898-0,3197 * * x$ & 7,51 & 97 \\
\hline Proteína bruta & 57,48 & 46,78 & 38,00 & 39,82 & $\hat{y}=73,317-0,6177 * * x$ & 14,76 & 81 \\
\hline Energia bruta & 61,01 & 55,97 & 53,90 & 56,10 & $\hat{y}=64,301-0,1679 * x$ & 6,97 & 51 \\
\hline Extrato etéreo & 66,22 & 63,98 & 63,54 & 55,45 & $\hat{y}=77,037-0,3276^{* *} x$ & 8,60 & 80 \\
\hline Carboidratos totais & 63,47 & 59,51 & 57,60 & 53,44 & $\hat{y}=72,914-0,3202 * * x$ & 10,71 & 98 \\
\hline Carboidratos não-fibrosos & 83,56 & 79,92 & 77,06 & 77,53 & $\hat{y}=88,944-0,2095^{* *} \mathrm{x}$ & 5,25 & 82 \\
\hline Fibra em detergente neutro & 38,81 & 36,73 & 36,54 & 31,97 & $\hat{\mathrm{y}}=36,01^{\mathrm{NS}}$ & 20,60 & - \\
\hline Fibra em detergente ácido & 34,57 & 28,21 & 22,38 & 24,49 & $\hat{y}=43,647-0,3607 * * x$ & 14,18 & 76 \\
\hline Nutrientes digestíveis totais 1 & 66,77 & 60,56 & 57,02 & 53,70 & - & - & - \\
\hline Nutrientes digestíveis totais ${ }^{2}$ & 73,09 & 70,36 & 67,79 & 64,27 & - & - & - \\
\hline
\end{tabular}

NS não-significativo; ** $(\mathrm{P}<0,01) ; *(\mathrm{P}<0,05)$.

1 Sniffen et al. (1992).

2 NRC (2001).

Os resultados encontrados neste trabalho para a digestibilidade aparente da MS estão abaixo dos observados por Silva et al. (2007), de 71,30; 65,16; 57,51 e 46,92\% para os níveis de 20, 40, 60 e $80 \%$ de feno de maniçoba, respectivamente, na alimentação de ovinos na fase de recria. Todavia, foram próximos dos observados por Barros et al. (1990) utilizando 100\% de feno de maniçoba na alimentação de ovinos $(66,8 \%)$.

A análise de regressão para o coeficiente de digestibilidade aparente da MO indicou redução de $0,3197 \%$ a cada $1 \%$ de feno na dieta. Silva et al. (2007) obtiveram maiores coeficientes de digestibilidade da MO para rações com menores porcentagens de volumoso. A digestibilidade da MO está relacionada ao teor energético da dieta (NDT), portanto este decréscimo pode ser atribuído à redução dos teores de NDT das dietas experimentais com o aumento da participação do feno.

$\mathrm{O}$ aumento na proporção de feno nas dietas proporcionou efeito linear decrescente $(\mathrm{P}<0,01)$ para os coeficientes de digestibilidade aparente da PB, uma vez que, a cada $1 \%$ de feno acrescentado na dieta, houve redução de $0,6177 \%$ na digestibilidade desse nutriente. Silva et al. (2007) associaram a redução na digestibilidade da PB ao aumento da participação do feno na dieta, que, por sua vez, aumentou a concentração de NIDA (nitrogênio insolúvel em detergente ácido).

A digestibilidade aparente daEB apresentou decréscimo de $0,1619 \%$ a cada $1 \%$ de participação do feno de maniçoba 
na dieta $(\mathrm{P}<0,05)$. Vários fatores afetam a digestibilidade da $\mathrm{EB}$, entre eles a concentração de FDN e FDA das dietas quando diminuem a densidade energética da dieta pela redução dos CNF.

Observou-se também efeito linear decrescente $(\mathrm{P}<0,01)$ dos coeficientes de digestibilidade de FDA, carboidratos totais e CNF com a elevação do feno nas dietas. Esse resultado pode ser atribuído à maior concentração de carboidratos estruturais, que são menos digestíveis. Considerações semelhantes foram feitas por Araújo et al. (1998), Dias et al. (2000) e Silva et al. (2007). Comportamento semelhante foi observado para a digestibilidade aparente do EE e pode ser explicado pela diminuição nos teores EE das rações com maiores níveis de feno.

A digestibilidade da FDN não foi influenciada pelo aumento da porcentagem de feno $(\mathrm{P}>0,05)$ e apresentou o valor médio de $36,01 \%$. O pH ruminal manteve-se dentro de limites fisiológicos normais em todos os níveis de feno e não houve redução no número de bactérias celulolíticas, principais responsáveis pela digestão da fibra. Outra explicação para a não-significância desta variável pode ser o seu elevado coeficiente de variação $(20,60 \%)$.

As concentrações energéticas estimadas foram superiores às observadas, para todos os tratamentos (Tabela 5). Magalhães et al. (2004) verificaram o mesmo comportamento com vacas mestiças em lactação. De acordo com esses autores, esse comportamento já era esperado, pois, segundo advertência do NRC (2001), os valores de energia para alimentos e dietas são baseados apenas nas características químicas e estas características limitam a disponibilidade de energia. Entretanto, a composição da dieta total e o consumo de MS têm marcantes efeitos na digestibilidade. Além disso, dietas que não promovem ótima fermentação ruminal podem ter os valores de energia superestimados e efeitos associativos positivos não são considerados.

Uma possível explicação para os menores coeficientes de digestibilidade dos nutrientes das rações neste estudo seria a baixa recuperação do indicador interno FDA indigestível nas fezes, conforme sugerido por Cochram et al. (1986). De fato, esses autores, ao avaliarem a digestibilidade da MS pelo método in vivo (coleta total de fezes) e aquelas estimadas pelos indicadores FDA eFDN indigestíveis, verificaram alta variabilidade entre as digestibilidades dos alimentos testados. Resultados semelhantes foram encontrados por Ataíde Jr. et al. (2001) em bovinos nelores não-castrados. Contudo, Berchielli et al. (2000), avaliando diferentes indicadores em estudos com novilhos em confinamento, observaram que tanto a FDA como a FDN indigestível forneceram valores semelhantes aos obtidos pelo método de coleta total das fezes.
Os resultados de consumo e da digestibilidade dos nutrientes em cabras de aptidão leiteira da raça Moxotó sugerem a necessidade de alteração do manejo da maniçoba em ocorrência natural para fenação. No período de seca, deve-se fazer um corte de uniformização nas plantas para redução dos ramos lenhosos e obtenção de feno com fibra de melhor qualidade visando melhoria na digestibilidade dos nutrientes.

\section{Conclusões}

A utilização de até $60 \%$ de feno de maniçoba em dietas para cabras Moxotó em lactação não altera o consumo de matéria seca, mas promove redução no consumo de nutrientes digestíveis totais e nos coeficientes de digestibilidade de todos os nutrientes, exceto da fibra em detergente neutro.

\section{Literatura Citada}

AGRICULTURAL AND FOOD RESEARCH COUNCIL - AFRC. The nutrition of goat. New York: CAB International, 1998. p.91-97.

ARAÚJO, G.G.L.; SILVA, J.F.C.; VALADARES FILHO, S.C. et al. Consumo e digestibilidade total dos nutrientes de dietas contendo diferentes níveis de volumoso, em bezerros. Revista Brasileira de Zootecnia, v.27, n.2, p.345-354, 1998.

ARAÚJO, G.G.L.; HOLANDA JR., E.V.; OLIVEIRA, M.C. Alternativas atuais e potenciais de alimentação de caprinos e ovinos nos períodos secos no semi-árido brasileiro. In: SIMPÓSIO INTERNACIONAL SOBRE CAPRINOS E OVINOS DE CORTE, 2., 2003, João Pessoa. Anais... João Pessoa: EMEPA, 2003. v.1, p.553-564.

ATAÍDE JR., J.R.; PEREIRA, O.G.; VALADARES FILHO, S.C. et al. Consumo, digestibilidade e desempenho de novilhos alimentados com rações à base de feno de capim-Tifton 85 , em diferentes idades de rebrota. Revista Brasileira de Zootecnia, v.30, n.1, p.215-221, 2001.

BARROS, N.N.; SALVIANO, L.M.C.; KAWAS, J.R. Valor nutritivo de maniçoba para caprinos e ovinos. Pesquisa Agropecuária Brasileira, v.25, n.3, p.387-392, 1990.

BERCHIELLI, T.T.; ANDRADE, P.; FURLAN, C.L. Avaliação de indicadores internos em ensaios de digestibilidade. Revista Brasileira de Zootecnia, v.29, n.3, p.830-833, 2000.

CASTRO, J.M.C.; SILVA, D.S.; MEDEIROS, A.N. et al. Desempenho de cordeiros Santa Inês alimentados com dietas completas contendo feno de maniçoba. Revista Brasileira de Zootecnia, v.36, n.3, p.674-680, 2007.

COCHRAN, R.C.; ADAMS, D.C.; WALLACE, J.D. et al. Predicting digestibility of different diets with internal markers: evaluation of four potential markers. Journal of Animal Science, v.63, 1476-1483, 1986.

DIAS, H.L.C.; VALADARES FILHO, S.C.; SILVA, J.F.C. et al. Consumo e digestões totais e parciais em novilho F1 limousin $x$ nelore alimentados com cinco níveis de concentrado. Revista Brasileira de Zootecnia, v.29, n.2, p.545-554, 2000.

FARIA, V.P. Rações completas para vacas em lactação, In: PEIXOTO, A.M.; MOURA, J.C.; FARIA, V.P. (Eds.) Confinamento de bovinos leiteiros. Piracicaba: Fundação de Estudos Agrários “Luiz Queiroz”, 1993. p.229-244. 
GOETSCH, A.L.; DETWEILER, G.; SAHLU, T. et al. Dairy goat performance with different dietary concentrate levels in late lactation. Small Ruminant Research, v.41, p.117-125, 2001.

GONÇALVES, A.L.; LANA, R.P.; RODRIGUES, M.T. et al. Padrão nictemeral do $\mathrm{pH}$ ruminal e componentes alimentar de cabras leiteiras alimentadas com dietas contendo diferentes relações volumoso:concentrado. Revista Brasileira de Zootecnia, v.30, n.6, p.1886-1892, 2001.

HALL, M.B.; HOOVER, W.H.; JENNINGS, J.P. et al. A method for partitioning neutral detergent soluble carbohydrates. Journal Science Food Agriculture, v.79, p.2079-2086, 1999.

HERD, T. Digestão: processos fermentativos. In: CUNNINGHAM, J.C. (Ed.) Tratado de fisiologia veterinária. Rio de Janeiro: Guanabara Koogan, 1993. p.222-241.

HUSSAIN, Q.; HAVREVOLL, Ø.; EIK, L.O. Effect of type roughage on feed intake, milk yield and body condition of pregnant goats. Small Ruminant Research, v.22, p.131-139, 1996.

KAWAS, J.R.; LOPES, J.; DANELON, D.L. et al. Influence of forage-to-concentrate ratios on intake, digestibility, chewing and milk production of dairy goats. Small Ruminant Research, v.4, p.11-18, 1991 .

LICITRA, G.; HERNANDEZ, T.M.; Van SOEST, P.J. Standardization of procedures for nitrogen fractionation of ruminant feeds. Animal Feed Science and Technology, v.57, n.11, p.347$358,1996$.

MAGALHÃES, M.C.S.; VÉRAS, A.S.C.; CARVALHO, F.F.R. et al. Inclusão de cama de frango em dietas à base de palma forrageira (Opuntia ficusindica Mill) para vacas mestiças em lactação. 2. Digestibilidade aparente. Revista Brasileira de Zootecnia, v.33, n.6, p.1909-1919, 2004 (Supl. 1).

MERTENS, D.R. Regulation of forage intake. In: FAHEEY JR., G.C. (Ed.) Forage quality, evaluation and utilization. Madison: American Society of Agronomy, 1994. p.450-493.

MERTENS, D.R. Análise da fibra e sua utilização na avaliação e formulação de rações. In: SIMPÓSIO INTERNACIONAL DE RUMINANTES, REUNIÃO ANUAL DA SOCIEDADE BRASILEIRA DE ZOOTECNIA, 29., 1992, Lavras. Anais... Lavras: Sociedade Brasileira de Zootecnia, 1992. p.188-219.
NATIONAL RESEARCH COUNCIL - NRC. Nutrient requirements of dairy goats. Washington, D.C.: National Academic Press, 1981. 110p

NATIONAL RESERARCH COUNCIL - NRC. Nutrient requirements of dairy cattle. 6.rev.ed. Washington, D.C.: National Academy Press, 1989. 158p.

NATIONAL RESEARCH COUNCIL - NRC. Nutrient requirements of the dairy cattle. 7.ed. Washington: D.C.: National Academy Press, 2001. 363p.

STATISTICAL ANALYSIS SYSTEM - SAS. User's guide: statistics. Versão 6.12. Cary: North Carolina State University, 1996. $956 \mathrm{p}$.

SILVA, J.F.C.; LEÃO, M.I. Fundamentos de nutrição dos ruminantes. Piracicaba: Livroceres, 1979. 380p.

SILVA, D.J.; QUEIROZ, A.C. Análise de alimentos: métodos químicos e biológicos. Viçosa, MG : Editora UFV, 2002. 235p.

SILVA, J.H.V.; RODRIGUES, M.T.; CAMPOS, J. Desempenho de cabras leiteiras recebendo dietas com diferentes relações volumoso:concentrado. Revista Brasileira de Zootecnia, v.28, n.6, p.1412-1418, 1999.

SILVA, D.S.; CASTRO, J.M.C.; MEDEIROS, A.N. et al. Feno de maniçoba em dietas para ovinos: consumo de nutrientes, digestibilidade aparente e balanço nitrogenado. Revista Brasileira de Zootecnia, v.36, n.5, p.1685-1690, 2007 (supl.).

SNIFFEN, C.J.; O'CONNOR, J.D.; Van SOEST, P.J. et al. A net carbohydrate and protein system for evaluating cattle diets: II. Carbohydrate and protein availability. Journal of Animal Science, v.70, p.3562-3577, 1992.

SOARES, J.G.G.; SALVIANO, L.M.C. Cultivo de maniçoba para produção de forragem no semi-árido brasileiro. Petrolina: Embrapa Semi-Árido, 2000 (Instruções Técnicas, 33). $6 \mathrm{p}$.

Van SOEST, P.J. Development of a comprehensive system of feed analysis and its applications to forages. Journal of Animal Science, v.26, n.1, p.119-128, 1967.

ZAMBOM, M.A.; ALCALDE, C.R.; SILVA, K.T. et al. Ingestão, digestibilidade das rações e produção de leite em cabras Saanen submetidas a diferentes relações volumoso:concentrado na ração. Revista Brasileira de Zootecnia, v.34, n.6, p.25052514, 2005 (supl.). 